\title{
Estimate of surface direct radiative forcing of desert dust from atmospheric modulation of the aerosol optical depth
}

\author{
A. di Sarra ${ }^{1}$, D. Fuà ${ }^{2}$, and D. Meloni ${ }^{1}$ \\ ${ }^{1}$ Laboratory for Earth Observations and Analyses, ENEA, Rome, Italy \\ ${ }^{2}$ Department of Physics, Sapienza University of Rome, Italy
}

Correspondence to: A. di Sarra (alcide.disarra@enea.it)

Received: 12 November 2012 - Published in Atmos. Chem. Phys. Discuss.: 8 January 2013

Revised: 30 April 2013 - Accepted: 10 May 2013 - Published: 10 June 2013

\begin{abstract}
Measurements carried out on the island of Lampedusa, in the central Mediterranean, on 7 September 2005, show the occurrence of a quasi-periodic oscillation of aerosol optical depth, column water vapour, and surface irradiance in different spectral bands. The oscillation has a period of about $13 \mathrm{~min}$ and is attributed to the propagation of a gravity wave able to modify the vertical structure of the planetary boundary layer, as also confirmed by satellite images. The wave occurred during a Saharan dust event. The oscillation amplitude is about 0.1 for the aerosol optical depth, and about $0.4 \mathrm{~cm}$ for the column water vapour. The modulation of the downward surface irradiances is in opposition of phase with respect to aerosol optical depth and water vapour column variations. The perturbation of the downward irradiance produced by the aerosols is determined by comparing the measured irradiances with estimated irradiances at a fixed value of the aerosol optical depth, and by correcting for the effect of the water vapour in the shortwave spectral range. The direct radiative forcing efficiency, i.e., the radiative perturbation of the net surface irradiance produced by a unit of optical depth aerosol layer, is determined at different solar zenith angles as the slope of the irradiance perturbation versus the aerosol optical depth. The estimated direct surface forcing efficiency at about $60^{\circ}$ solar zenith angle is $-(181 \pm 17) \mathrm{W} \mathrm{m}^{-2}$ in the shortwave, and $-(83 \pm 7) \mathrm{W} \mathrm{m}^{-2}$ in the photosynthetic spectral range. The estimated daily average forcing efficiencies are of about -79 and $-46 \mathrm{~W} \mathrm{~m}^{-2}$ for the shortwave and photosynthetic spectral range, respectively.
\end{abstract}

\section{Introduction}

Relatively large uncertainties exist in the determination of the role of atmospheric aerosols on the radiative budget, and on the direct forcing produced by aerosols at the earth's surface. Satheesh and Ramanathan (2000) suggested the combined use of measurements of aerosol optical depth and shortwave radiation net irradiances at the surface to estimate the shortwave direct aerosol forcing. This approach does not require the use of radiative transfer models for the evaluation of the aerosol-free shortwave irradiance, and of the assumptions required in the modelling exercise.

The so called direct method has been used by several authors to derive the aerosol forcing in different regions and with different aerosol components and conditions (e.g., Jayaraman et al., 1998; Conant, 2000; Podgornyi et al., 2000; Satheesh and Ramanthan, 2000; Meywerk and Ramanathan, 2002; Markowicz et al., 2002; Bush and Valero, 2002; di Sarra et al., 2008; Di Biagio et al., 2009, 2010).

A relatively large dataset, covering at least several months of data, is required to derive the forcing with the direct method. The use of data from a relatively wide temporal interval implies that different classes of particles and, within the same aerosol class, particles with different properties are included simultaneously in the analysis.

di Sarra et al. (2008) have applied this method to the central Mediterranean and derived estimates of the aerosol forcing for different aerosol classes, namely desert dust, polluted, and biomass burning particles. In a more recent analysis these aerosol types are further divided in different sub-classes, depending on the observed value of the single scattering albedo, SSA (Di Biagio et al., 2009, 2010). The 
obtained results suggest a dependency on both the aerosol type and the SSA.

In this study we derive the aerosol forcing from high temporal resolution measurements of aerosol optical depth and surface radiative fluxes during the occurrence of a hydrodynamic oscillation of the boundary layer, probably related with the propagation of a gravity wave. The oscillation in the aerosol optical depth associated with the wave induces a quasi-periodic change in the downward shortwave irradiance, and provides the opportunity to derive an estimate of the aerosol direct forcing in a short time period. The method has been applied to one event observed at Lampedusa $\left(35.5^{\circ} \mathrm{N}, 12.6^{\circ} \mathrm{E}\right)$, in the central Mediterranean, characterized by transport of Saharan dust.

\section{Observations}

Observations collected at Lampedusa during the morning of 7 September 2005 display a quasi-periodic modulation of aerosol optical depth, column water vapour, and downward shortwave irradiance. The occurrence of such a phenomenon at Lampedusa in the daytime and with cloud-free conditions is seldom observed: out of several years of aerosol optical depth (see e.g., Meloni et al., 2007, 2008) only three cases were clearly identified. One was observed on $22 \mathrm{Au}-$ gust 2007; however, in this case the variation in optical depth is small (0.02-0.03) and the retrieval of the forcing is unpractical with the proposed method. A third event took place in October 2011 and will be investigated separately.

The aerosol optical depth, Ångström exponent, and column water vapour are derived from multi-filter rotating shadowband radiometer (MFRSR; Harrison et al., 1994) measurements. The MFRSR measures downward global and diffuse irradiances in seven channels. Six channels have a full width, half-maximum bandwidth of about $10 \mathrm{~nm}$, and are centred at 416, 500, 617, 671, 869, and $940 \mathrm{~nm}$, respectively. The seventh is a broadband channel, which detects radiation between 300 and $1100 \mathrm{~nm}$. In this study we use aerosol optical depths at 500 and $869 \mathrm{~nm}$. The aerosol optical depth is derived from the direct irradiance, calculated as the difference between global and diffuse irradiances, by applying the Bouguer law. The Ångström exponent is calculated from the aerosol optical depths at 500 and $869 \mathrm{~nm}$. Details on the retrieval method and associated errors are given by Pace et al. (2006). The column water vapour is derived from the MFRSR direct irradiance at $940 \mathrm{~nm}$. The signal at $940 \mathrm{~nm}$ is calibrated with the modified Langley plot method against integrated water vapour data from radiosondes, and the column water vapour is derived from the measured transmissivity in this channel, as described by Liberti et al. (2010).

The downward shortwave (SW) irradiance is measured with an Eppley Precision Spectral Pyranometer (PSP), while the downward photosynthetic active radiation (PAR) is obtained with a Licor LI-190 sensor. The evolution of short-

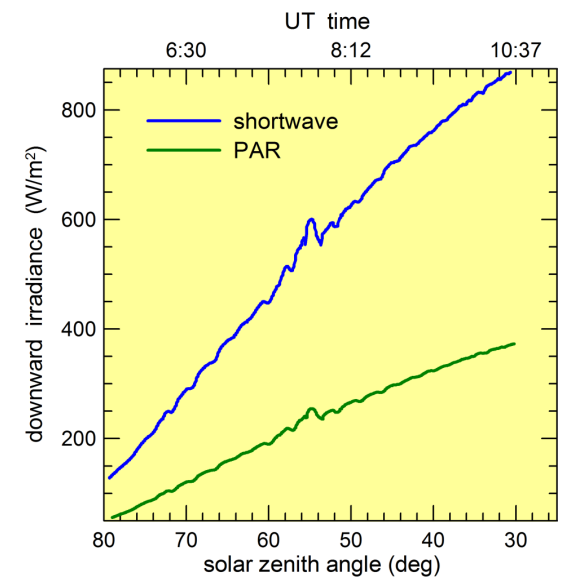

Fig. 1. Evolution of the downward shortwave and PAR irradiances measured at Lampedusa during the morning of 7 September 2005.

wave and photosynthetic active irradiances during the morning of 7 September 2005 is shown in Fig. 1. PSP data are corrected for the thermal offset and cosine response as described by Di Biagio et al. (2009). The PSP data are referred to a second PSP calibrated at the PMOD/World Radiation Centre at Davos (Switzerland) in September 2005. The PAR radiometer was calibrated at the factory in 2002; its calibration was updated in April 2007 against a freshly calibrated PAR. In this period the calibration constant changed by about $6 \%$, and the adopted value was obtained by temporal interpolation at the time of the measurements.

All irradiance measurements display a quasi-periodic variation superimposed on the overall increasing trend occurring in the morning. A periodic change in the diffuse irradiance is also recorded by a TSI-440 total sky imager (TSI), also operational at Lampedusa (not shown). The TSI images do not show presence of clouds, except for a possibly very thin cloud close to the Sun during the period 07:19-08:10 UTC. The influence of the cloud on the downward irradiance is evident in Fig. 1, and data from this time interval are excluded from the analysis.

The ratio between PAR and SW downward irradiance varies between 0.41 and 0.43 ; these values are in agreement with measurements of this ratio at other Mediterranean sites (Jacovides et al., 2007).

Figure 2 displays the evolution of the aerosol optical depth at $500 \mathrm{~nm}, \tau$, and of the column water vapour, cwv. The aerosol optical depth varies between 0.29 and 0.41 , while $\mathrm{cwv}$ varies between 2.4 and $2.8 \mathrm{~cm}$. The oscillations of $\tau$ and $\mathrm{cwV}$ are in phase. The period of the oscillation is about 13 minutes; 17 maxima in $\tau$ are observed between 05:53 and 09:29 UTC. In the same time interval the solar zenith angle varies between $77.5^{\circ}$ and $37.2^{\circ}$. The maximum amplitude of the aerosol optical depth oscillation is about 0.1 around 07:30 UTC, and progressively reduces afterwards. The surface pressure is measured at Lampedusa every $10 \mathrm{~min}$; the 


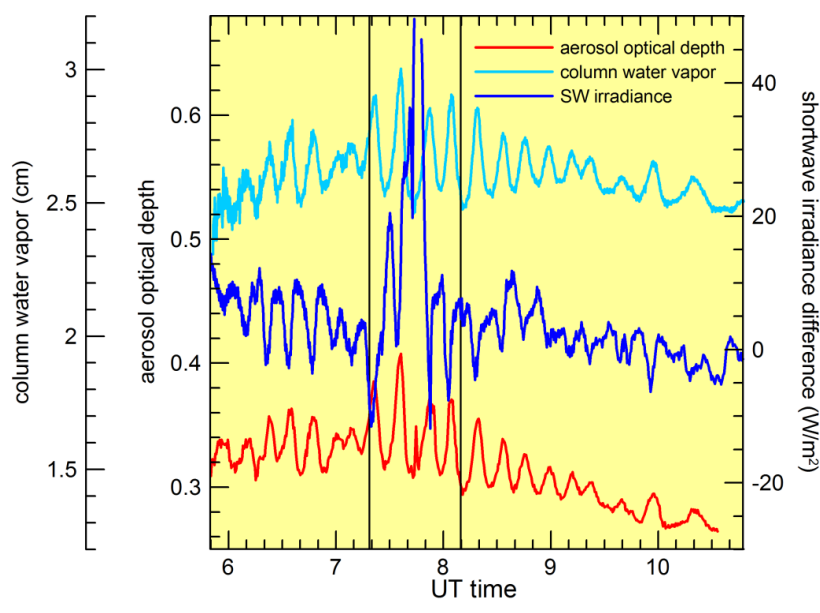

Fig. 2. Evolution of aerosol optical depth at $500 \mathrm{~nm}$, column water vapour, and of the difference between the measured downward shortwave irradiance and the irradiance estimated at fixed aerosol optical depth and column water vapour (see text) during the morning of 5 September 2007. The region between the two vertical lines corresponds to the presence of thin clouds in the sky imager pictures.

relative maxima and minima (although measurements every 10 min under sample the oscillation) are in phase with the maxima of the aerosol optical depth.

The observed oscillation is attributed to the presence of a gravity wave propagating through the southern Mediterranean. The radiosonde profiles measured at Tunis $\left(36.8^{\circ} \mathrm{N}\right.$, $10.2^{\circ} \mathrm{E}$ ) on 7 September 2005 at 00:00 and at 12:00 UTC are compatible with the development of gravity waves in the troposphere, with a phase velocity of about $8 \mathrm{~m} / \mathrm{s}$ from the NW direction. The critical level, where the phase velocity of the wave matches the horizontal velocity of the wind and the Richardson number reaches a minimum value of 0.05 is at about $3200 \mathrm{~m}$ a.s.l.

We assume that the propagation of a gravity wave produced a modulation of the troposphere, which, in turn, may have influenced the column amount of atmospheric constituents, such as water vapour and aerosols. In fact, a gravity wave propagating in the atmosphere perturbs the local background concentration of any conservative constituent and in a simplified linear treatment such perturbation can be described by a function oscillating at a defined frequency whose amplitude is strongly dependent on the spatial coordinates, in particular on the vertical coordinate where it also often displays an oscillatory behaviour. The possibility that the optical depth is oscillating with the same frequency of the wave needs some requirements, in particular that the vertical integral of a properly weighed perturbation of the vapour/aerosol concentration is different from zero. Such requirement can be fulfilled only if the layer of constituents assumed to be the main cause of the solar radiation extinction is confined within a region where the vertical structure

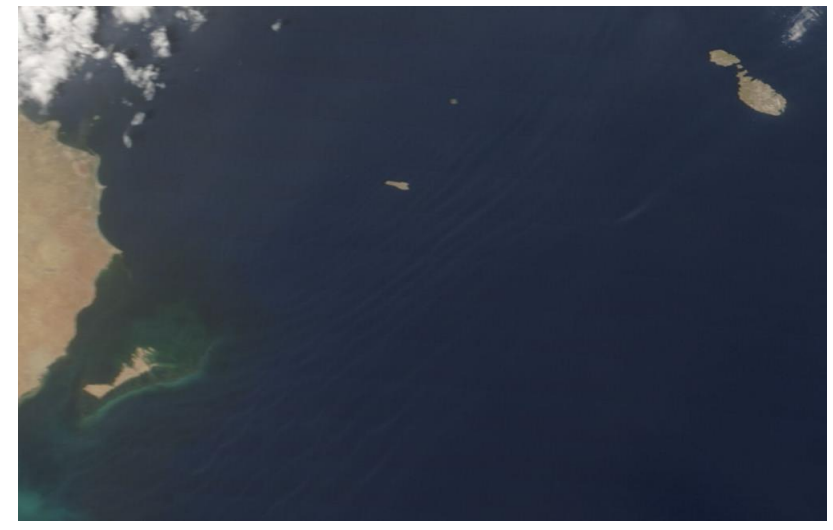

Fig. 3. True colour image of the central Mediterranean from the MODIS instrument on board the Terra satellite for 7 September 2005, at 09:25 UTC. Lampedusa is in the centre of the image; the Tunisian coast is on the left, and Malta in the upper right corner. The modulation of the aerosol produced by the wave propagation is evident southeast of Lampedusa.

of the gravity wave displays only one maximum, i.e., it is confined within half vertical wavelength of the wave structure. Such condition depends critically on the structure of the background atmosphere and on the vapour/aerosol background profile and must be analysed for each individual case. If the layer of optically active constituents is limited within the boundary layer, the above condition is usually verified as stability analyses present in the literature show; see for example the vertical structure of the waves in Mastrantonio et al. (1976) and Fua and Einaudi (1984). A more detailed study of this case is needed and will be the subject of a future paper. Here we may only state that it is highly probable that the observed oscillations in the aerosol optical depth and column water vapour are indeed produced by a gravity wave propagating through the atmosphere at that time.

A Moderate Resolution Imaging Spectroradiometer (MODIS) true colour image of the central Mediterranean taken on 7 September 2005, at 09:25 UTC, is shown in Fig. 3. The image nicely shows the propagation of the wave, and the associated modulation of the dust load. As shown in Fig. 2, this image corresponds to the tail of the wave at Lampedusa, and confirms that the wave propagates from northwest.

Observations of column water vapour oscillations, with development of clouds, associated with the propagation of gravity waves have been previously reported by Reinking et al. (2000). The influence of gravity waves on vertically integrated quantities for a non-rotating model of the tropical atmosphere is studied by Raymond and Fuchs (2007).

The backward air mass trajectories reaching Lampedusa on 7 September 2005 overpass northern Libya (trajectories arriving below $2000 \mathrm{~m}$ ), Tunisia and northern Algeria (trajectories arriving above $2000 \mathrm{~m}$ ), carrying Saharan dust particles to Lampedusa. The trajectories are calculated at 08:00 UTC, using the Hybrid particle dispersion model 
(HYSPLIT, Draxler and Rolph, 2012). The aerosol optical properties measured during the morning of 7 September 2005, are typical of cases dominated by Saharan dust (e.g. Pace et al., 2006; Meloni et al., 2006, 2007): the aerosol Ångström exponent is between 0.5 and 0.6 during the morning. The change in the Ångström exponent is small and not correlated with the oscillation of the optical depth. Thus, we assume that the changes in aerosol microphysical properties are small throughout the morning and changes in optical depth are primarily due to changes in aerosol number density.

As will be discussed in detail below, the variations in downward irradiance shown in Fig. 1 are in opposition of phase with respect to changes in aerosol optical depth and water vapour column amount, suggesting a negative aerosol shortwave forcing at the ground.

A change in the column amount of other atmospheric constituents, in addition to aerosol and water vapour, may contribute to the modulation of the solar radiation. More than 20 measurements of total ozone were carried out with a Brewer spectrophotometer at Lampedusa during the morning of 7 September, 2005. The average and standard deviation over the morning is $(287.1 \pm 1.3)$ DU. Measurements show very limited changes in total ozone, not correlated with the gravity wave. This is expected since total ozone is mainly determined by the stratospheric contribution. The maximum change is of about 6 DU. Radiative transfer calculations show that the influence of this change on the downward shortwave irradiance is totally negligible $\left(\ll 1 \mathrm{~W} \mathrm{~m}^{-2}\right)$.

Changes in the $\mathrm{SO}_{2}$ and $\mathrm{NO}_{2}$ column may marginally contribute to modulate the SW irradiance. Brewer observations show that column $\mathrm{SO}_{2}$ remains very low $(<2 \mathrm{DU})$ throughout the morning, and no measurable influence is expected. Similarly, due to the very limited presence of $\mathrm{NO}_{2}$ sources and its short lifetime, no influence is expected from this gas. Thus, aerosols and water vapour are by far the most relevant factors producing changes in the solar irradiance.

The combined modulation of downward irradiance, water vapour column, and aerosol optical depth is used to estimate the aerosol effect on the irradiance. From the irradianceoptical depth relation, the aerosol surface direct forcing efficiency is derived, under the assumption that during the measurement interval the aerosol microphysical properties do not appreciably change. The water vapour column amount is used to take into account and correct for the influence of the water vapour changes on the shortwave irradiance. The derivation of the forcing efficiency is described in detail in the next section.

\section{Aerosol forcing}

Using the direct method, the direct aerosol forcing efficiency can be derived uniquely from observations by plotting the net irradiance versus the aerosol optical depth, and calculating the slope of the fitting linear relationship. The slope is equal to the forcing produced by an aerosol layer whose optical depth is equal to 1 . In our case, the determination of the aerosol forcing is based on the estimate of the variation in the downward irradiance produced by a variation in aerosol optical depth. The downward irradiance depends largely on the solar zenith angle, and consequently, on time. In order to identify the aerosol effect, a reference downward irradiance, which includes the effect of changes in solar zenith angle, but not aerosol optical depth and water vapour column, needs to be defined.

\subsection{Water vapour column}

All PSP measurements are scaled to the column water vapour amount of $2.6 \mathrm{~cm}$, using the expression

$F(\tau, \mathrm{cwv}=2.6 \mathrm{~cm}, \theta)=F(\tau, \mathrm{cwv}, \theta)[1+f(\theta)(2.6-\mathrm{cwv})]$,

where $f$ gives the relative change in downward irradiance per change in cwv, and is estimated using the SBDART model (Ricchiazzi et al., 1998) for different solar zenith angles, $\theta$, and water vapour amounts. The value of $f$ ranges between 0.02 (at low solar zenith angle) and 0.03 (at $75^{\circ}$ solar zenith angle) $\mathrm{cm}^{-1}$. The value of (2.6-cwv) is comprised between -0.2 and $0.2 \mathrm{~cm}$ in the investigation period, and the correction to the downward irradiances due to the water vapour changes are always smaller than $0.6 \%$ (less than $3.5 \mathrm{~W} \mathrm{~m}^{-2}$ at $35^{\circ}$ solar zenith angle, and less than $1.4 \mathrm{~W} \mathrm{~m}^{-2}$ at $75^{\circ}$ ).

\subsection{Aerosol optical depth}

The reference irradiance $R(\theta)$ is derived by fitting the watervapour-corrected PSP irradiances taken at a fixed value of the optical depth with the following expression:

$$
R\left(\theta, \tau_{f}\right)=a_{1}+a_{2} \cos (\theta)+a_{3}[\cos (\theta)]^{2} .
$$

Two values of $\tau_{f}$ were chosen in two different time intervals: $\tau_{f}=0.315$ in the time interval 05:50-08:59 UTC (having excluded the interval 07:09-08:23), and $\tau_{f}=0.295$ in the interval 08:39-09:57. The $a_{1}, a_{2}$, and $a_{3}$ coefficients are derived for each of the two intervals, allowing for the derivation of the downward irradiances at fixed water vapour and aerosol optical depth as a function of the solar zenith angle or time. The two curves curve fit well the experimental data in both intervals.

The difference between the measured downward irradiance and $R(\theta)$ (fit for $\tau_{f}=0.315$ ) is also displayed in Fig. 2 . It must be noted that this difference includes the effects of both aerosol and water vapour, which affect the measured irradiance, while $R(\theta)$ is calculated at fixed cwv and $\tau$. The differences in downward irradiance are evidently linked and in opposition of phase with respect to the aerosol and water vapour variations. 

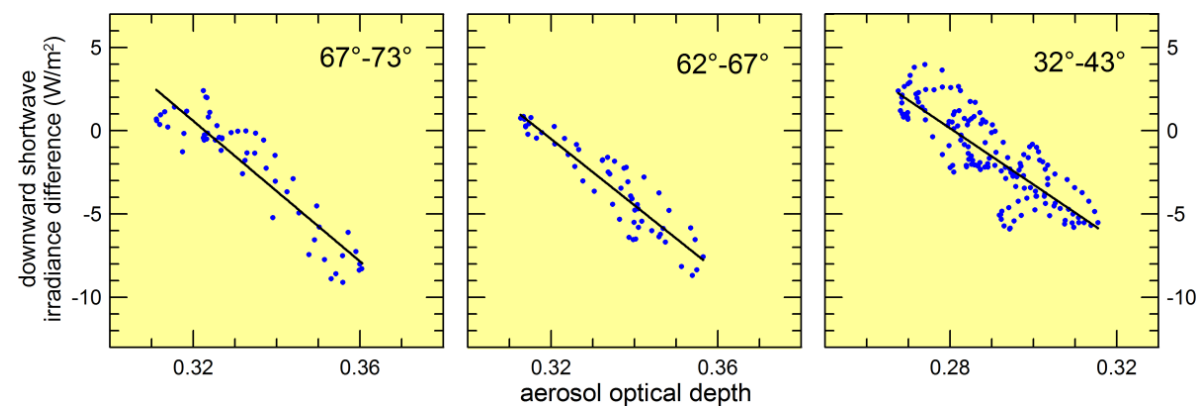

Fig. 4. Deviations of the measured downward shortwave irradiance at fixed column water vapour from the estimated irradiance at fixed water vapour and aerosol optical depth versus the measured aerosol optical depth, for three intervals of solar zenith angle.

\subsection{Forcing estimate}

The deviations of $F(\tau, \mathrm{cwv}=2.6 \mathrm{~cm}), \Delta F$, from the fitting curves (providing the downward irradiances at fixed water vapour and aerosol optical depth) are due to the influence of the aerosol variations from the reference value.

The values of $\Delta F$ are averaged over $1 \mathrm{~min}$ intervals and are plotted against the $1 \mathrm{~min}$ average of the aerosol optical depth in different solar zenith angle intervals, with the aim of taking into account the dependence of the forcing efficiency on the solar position. Solar zenith angle interval of five degrees around $75^{\circ}, 70^{\circ}, 65^{\circ}, 45^{\circ}, 40^{\circ}$, and $35^{\circ}$ solar zenith angles were adopted. Due primarily to the limited variability in aerosol optical depth, a poor linear correlation between $\Delta F$ and $\tau$ is found for the intervals centred at $75^{\circ}, 45^{\circ}, 40^{\circ}$, and $35^{\circ}$. Reliable results could be conversely obtained by aggregating the two intervals centred at $35^{\circ}$ and $45^{\circ}$, while the data around $75^{\circ}$ and $45^{\circ}$ were not used for the fit.

Figure 4 shows the behaviour of the SW radiation residuals reduced to a cwv of $2.6 \mathrm{~cm}$ versus the observed aerosol optical depth, separately for the three solar zenith angle intervals. The linear fits to the data, whose slope is $b$, are also displayed.

The slope of the fit $b$ is used to derive the forcing efficiency $F E$ with the expression

$F E=b(1-a)$,

where the term $(1-a)$ is needed to derive the surface net irradiance from the downward irradiances. The value of the albedo $a$ is calculated following Jin et al. (2004) taking into account the measured wind speed, and is a function of the solar zenith angle.

The accuracy of the determination of the forcing with this method depends primarily on the differences among irradiances and optical depths measured with the same instrument at short time intervals. Although all the instruments are regularly calibrated and controlled, the overall calibration of the sensors has a minor effect on the results. In addition, since the reference curve at fixed aerosol optical depth is determined from the same observations, the influence of possible instru- mental effects, such as the residual influence of the angular response of the radiometers, are minimized. The instrumental stability within the measurement time interval is very good, and differences in irradiances and optical depths, although small, are significant. Consequently, the uncertainty on $F E$ is estimated, taking into account only the uncertainty of the fit, calculated following Higbie (1991), and the estimated error on the correction for the water vapour changes. The influence of this correction may be relevant, due to the relatively large uncertainty on the water vapour column measurement, of the order of $15 \%$. The uncertainty on the slope is thus derived by taking into account the effect of a $15 \%$ variation in cwv, which contributes to the total uncertainty by about $12 \mathrm{~W} \mathrm{~m}^{-2}$, and the uncertainty associated with the fit.

The same procedure, except for the water vapour correction which is not required in the visible spectral range, was applied to the PAR measurements. Better linear fits are generally obtained from the PAR signals, and estimates of $F E$ could be derived also for the solar zenith angle interval around $45^{\circ}$. Figure 5 shows the obtained fits.

\section{Results and discussion}

Table 1 reports the values of the $F E$ for the SW and the photosynthetically active spectral ranges for the selected solar zenith angle intervals.

The average ratio between PAR and SW FEs is 0.55 , with an estimated uncertainty of the order of 0.1. The lowest ratio is found for large solar zenith angles, while the highest is found for $\theta$ of about $35^{\circ}$. At small solar zenith angle, the ratio between the PAR and SW forcing efficiencies is larger than the ratio between PAR and SW irradiance. This effect is attributed to three factors: the aerosol optical depth decreases with wavelength, and also its radiative effect; the presence of absorption bands, mainly by water vapour, at the longer wavelengths in the shortwave range leads to a reduced aerosol influence on the downward irradiance; the dust single scattering albedo is relatively low in the visible, and increases at longer wavelengths (e.g., Sokolik and Toon, 1996), producing a stronger aerosol impact on PAR than at longer 
Table 1. Estimated dust forcing efficiencies derived in the shortwave and PAR spectral ranges and in different time/solar zenith angle intervals.

\begin{tabular}{cccc}
\hline Time interval & $\begin{array}{c}\text { Solar zenith } \\
\text { angle interval }\end{array}$ & $\begin{array}{c}\text { SW FE } \\
\left(\mathrm{W} \mathrm{m}^{-2}\right)\end{array}$ & $\begin{array}{c}\text { PAR } F E \\
\left(\mathrm{~W} \mathrm{~m}^{-2}\right)\end{array}$ \\
\hline 06:14-06:45 UTC & $73^{\circ}-67^{\circ}$ & $-188 \pm 18$ & $-93 \pm 7$ \\
06:40-07:10 UTC & $67^{\circ}-62^{\circ}$ & $-181 \pm 17$ & $-83 \pm 7$ \\
08:23-08:58 UTC & $47^{\circ}-42^{\circ}$ & - & $-107 \pm 5$ \\
08:51-10:11 UTC & $43^{\circ}-32^{\circ}$ & $-163 \pm 16$ & $-112 \pm 3$ \\
\hline
\end{tabular}

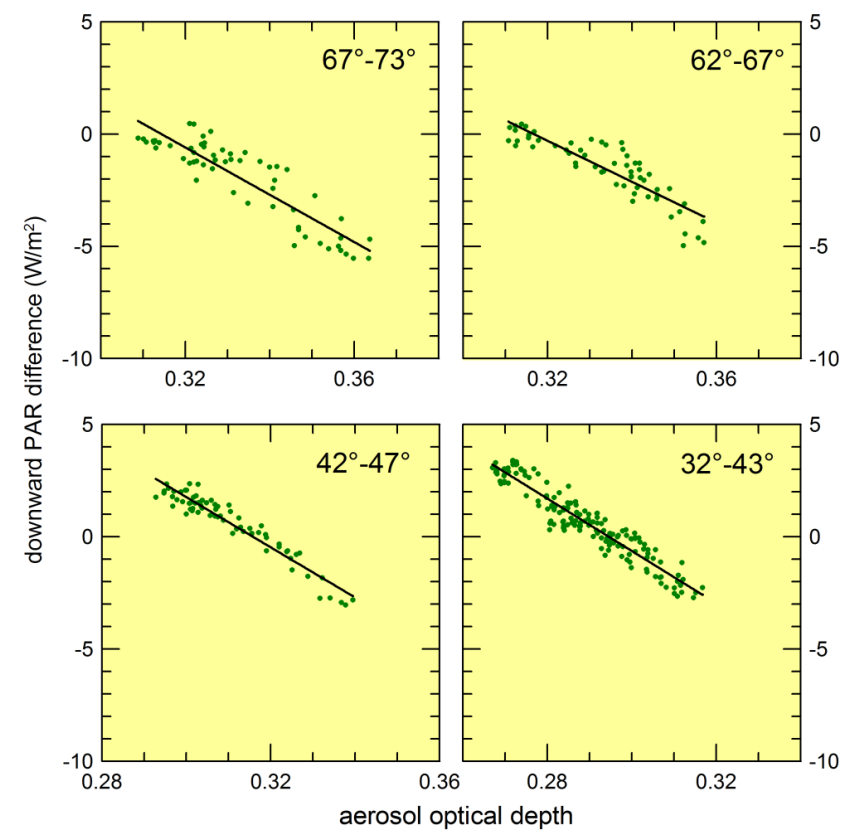

Fig. 5. Deviations of the measured downward PAR irradiance from the estimated PAR irradiance at fixed aerosol optical depth versus the measured aerosol optical depth, in four intervals of solar zenith angle.

wavelengths. The aerosol effect in the SW and PAR spectral ranges were also derived using radiative transfer model simulations carried out with the MODTRAN 4 (Berk et al., 2003) for the model desert dust properties and at the same solar zenith angles. The average ratio between the dust forcing in the PAR and SW spectral ranges is 0.62 , which is higher than the modelled PAR to SW irradiance ratio (0.44). As expected, the ratio depends on the dust optical properties.

The reader is reminded that the FEs reported in Table 1 are instantaneous values. A polynomial curve fitted to the values of Table 1 is calculated at different times and averaged over a whole day to derive an estimate of the daily average $F E$. The estimated daily average $F E$ is $-79 \mathrm{~W} \mathrm{~m}^{-2}$ for $\mathrm{SW}$ radiation, and $-46 \mathrm{~W} \mathrm{~m}^{-2}$ for PAR. Over the whole daily cycle the ratio between PAR and SW FE is 0.58 .
The daily SW forcing for the selected day, with an average aerosol optical depth of about 0.3 , is about $-24 \mathrm{~W} \mathrm{~m}^{-2}$ in the $\mathrm{SW}$, and is about $-14 \mathrm{~W} \mathrm{~m}^{-2}$ for PAR.

Estimates of the Saharan dust direct shortwave forcing efficiency over the Mediterranean sea by different authors are listed by Di Biagio et al. (2010). The reported daily average values span from -50 and $-80 \mathrm{~W} \mathrm{~m}^{-2}$ (Zhou et al., 2005). Previous studies at Lampedusa suggested values around $-68 \mathrm{~W} \mathrm{~m}^{-2}$ (di Sarra et al., 2008; Di Biagio et al., 2009, 2010). More recently, di Sarra et al. (2011) estimated an $F E$ of about $-55 \mathrm{~W} \mathrm{~m}^{-2}$ for a very intense dust event.

The determinations of the instantaneous value of the SW $F E$ are also within the range of values found in the literature. Previous determinations obtained at Lampedusa give values between -140 and $-220 \mathrm{~W} \mathrm{~m}^{-2}$ for $35^{\circ}$ solar zenith angle (di Sarra et al., 2008, 2011; Di Biagio et al., 2009, 2010). In a recent modelling study Gómez-Amo et al. (2011) derive values between -175 and $-250 \mathrm{~W} \mathrm{~m}^{-2}$ at $60^{\circ}$ solar zenith angle.

Meloni et al. (2005) estimated the radiative effect produced in the visible spectral range by two Saharan dust events occurred at Lampedusa in July 2002. They found a daily average surface $F E$ of about $-30 \mathrm{~W} \mathrm{~m}^{-2}$ for a case characterized by high aerosol single scattering albedo, and of about $-43 \mathrm{~W} \mathrm{~m}^{-2}$ for a case with low aerosol SSA.

\section{Conclusions}

Observations collected at Lampedusa, in the central Mediterranean, during an oscillation of the troposphere associated with the propagation of a gravity wave were used to derive an estimate of the Saharan dust radiative forcing. The oscillation occurred during a Saharan dust event on 7 September 2005, and is observed in the aerosol optical depth, column water vapour, and downward shortwave and PAR irradiances. The modulation of the aerosol optical depth is also evident in a MODIS image taken on the same morning, and confirm the existence of a wavelike structure propagating from the northwest into the central Mediterranean.

The oscillation of the downward irradiances are in opposition of phase with respect to changes in aerosol optical depth and water vapour column, and are attributed to the combined effect of these two factors. All SW irradiances are reported to the same cwv content, by using radiative transfer model calculations. Reference curves describing the downward SW and PAR irradiances are constructed by using measurements obtained at a fixed value of the aerosol optical depth. The radiative perturbation produced by dust is thus obtained as the difference between the measured irradiances, reported at $\mathrm{cwv}=2.6 \mathrm{~cm}$, and the reference curve at the same solar zenith angle.

The radiative forcing efficiencies are then determined at some values of the solar zenith angle as the slope of the linear 
fit of the radiative perturbation versus the measured aerosol optical depth.

The estimated value of the dust $F E$ is $-188 \mathrm{~W} \mathrm{~m}^{-2}$ for the SW and $-93 \mathrm{~W} \mathrm{~m}^{-2}$ for PAR for $\theta$ between $73^{\circ}$ and $67^{\circ},-163 \mathrm{~W} \mathrm{~m}^{-2}$ for the $\mathrm{SW}$ and $-112 \mathrm{~W} \mathrm{~m}^{-2}$ for PAR for $\theta$ between $43^{\circ}$ and $32^{\circ}$. The estimated daily average $F E$ is $-79 \mathrm{~W} \mathrm{~m}^{-2}$ for the $\mathrm{SW}$ range, and $-46 \mathrm{~W} \mathrm{~m}^{-2}$ for PAR. The obtained values are in good agreement with previous estimates for desert dust over the ocean. The ratio between PAR and SW FEs is higher than the ratio of the PAR to SW irradiance. This effect, which is confirmed by radiative transfer model calculations, is attributed to spectral changes of the dust optical properties, and the occurrence of strong water vapour absorption bands at the longer wavelength range.

The proposed method allows for the estimation of the radiative effect of the aerosols, in the presence of a natural oscillation of the atmosphere, by using a limited dataset; the method is robust with respect to a detailed instrumental characterization, since it is based mainly on direct observations from the same set of instruments. Although these oscillatory events are infrequent at Lampedusa, they may occur more frequently in regions with a different geographical setting; in these cases the proposed method might allow a better insight on the aerosol radiative effects in different conditions.

Acknowledgements. Contributions by C. Di Biagio, F. Monteleone, G. Pace, and D. M. Sferlazzo are gratefully acknowledged. This study was partially supported by the Italian Ministry for University and Research through projects Aeroclouds, NextData, and Ritmare. We acknowledge the use of Rapid Response imagery from the Land Atmosphere Near-real time Capability for EOS (LANCE) system operated by the NASA/GSFC/Earth Science Data and Information System (ESDIS) with funding provided by NASA/HQ.

Edited by: N. Mihalopoulos

\section{References}

Berk, A., Anderson, G. P., Acharya, P. K., Hoke, M. L., Chetwynd, J. H., Bernstein, L. S., Shettle, E. P., Matthew, M. W., and AdlerGolden, S. M.: MODTRAN4 Version 3 Revision 1 User's Manual, technical report, Air Force Resour. Lab., Hanscom Air Force Base, Lincoln, Mass., USA, 2003.

Bush, B. C. and Valero, F. P. J.: Spectral aerosol radiative forcing at the surface during the Indian Ocean Experiment (INDOEX), J. Geophys. Res., 107, 8003, doi:10.1029/2000JD000020, 2002.

Conant, W. C.: An observational approach for determining aerosol surface radiative forcing: Results from the first field phase of INDOEX, J. Geophys. Res., 105, 15347-15360, 2000.

Di Biagio, C., di Sarra, A., Meloni, D., Monteleone, F., Piacentino, S., and Sferlazzo, D.: Measurements of Mediterranean aerosol radiative forcing and influence of the single scattering albedo, J. Geophys. Res., 114, D06211, doi:10.1029/2008JD011037, 2009.

Di Biagio, C., di Sarra, A., and Meloni, D.: Large atmospheric shortwave radiative forcing by Mediterranean aerosol derived from simultaneous ground-based and spaceborne observations, and dependence on the aerosol type and single scattering albedo, J. Geophys. Res., 115, D10209, doi:10.1029/2009JD012697, 2010.

di Sarra, A., Pace, G., Meloni, D., De Silvestri, L., Piacentino, S., and Monteleone, F.: Surface shortwave radiative forcing of different aerosol types in the central Mediterranean, Geophys. Res. Lett., 35, L02714, doi:10.1029/2007GL032395, 2008.

di Sarra, A., Di Biagio, C., Meloni, D., Monteleone, F., Pace, G., Pugnaghi, S., and Sferlazzo, D.: Shortwave and longwave radiative effects of the intense Saharan dust event of 25-26 March 2010 at Lampedusa (Mediterranean sea), J. Geophys. Res., 116, D23209, doi:10.1029/2011JD016238, 2011.

Draxler, R. R. and Rolph, G. D.: HYSPLIT (HYbrid Single-Particle Lagrangian Integrated Trajectory) Model access via NOAA ARL READY Website (http://ready.arl.noaa.gov/HYSPLIT. php), NOAA Air Resources Laboratory, Silver Spring, MD, USA, 2012.

Fua, D. and Einaudi, F.: On the effect of dissipation on shear instabilities in the stable atmospheric boundary layer, J. Atmos. Sci., 41, 888-900, 1984.

Gómez-Amo, J. L., Pinti, V., Di Iorio, T., di Sarra, A., Meloni, D., Becagli, S., Bellantone, V., Cacciani, M., Fuà, D., and Perrone, M. R.: The June 2007 Saharan dust event in the central Mediterranean: Observations and radiative effects in marine, urban, and sub-urban environments, Atmos. Environ., 45, 5385-5493, 2011.

Harrison, L., Michalsky, J., and Berndt, J.: Automated multifilter rotating shadow-band radiometer: An instrument for optical depth and radiation measurements, Appl. Opt., 33, 5118-5125, 1994.

Higbie, J.: Uncertainty in the linear regression slope, Am. J. Phys., 59, 184-185, 1991.

Jacovides, C. P., Tymvios, F. S., Assimakopoulos, V. D., and Kaltsounides, N. A.: The dependence of global and diffuse PAR radiation components on sky conditions at Athens, Greece, Agricul. Forest Meteorol, 143, 277-287, 2007.

Jayaraman, A., Lubin, D., Ramachandran, S., Ramanathan, V., Woodbridge, E., Collins, W. D., and Zalpuri, K. S.: Direct observations of aerosol radiative forcing over the tropical Indian Ocean during the January-February 1996 pre-INDOEX cruise, J. Geophys. Res., 103, 13827-13836, 1998.

Jin, Z., Charlock, T., Smith Jr., W., and Rutledge, K.: A parameterization of ocean surface albedo, Geophys. Res. Lett., 31, L22301, doi:10.1029/2004GL021180, 2004.

Liberti, G. L., Centoni, F., Casasanta, G., di Sarra, A., Meloni, D., and Sferlazzo, D.: Ground-based and satellite observations of column water vapour in the central Mediterranean: spatiotemporal variability, Proceedings of the Symposium Earth Observation and Water Cycle Science, ESA Special Publication SP674, 2010.

Mastrantonio, G., Einaudi, F., Fua, D., and Lalas, D. P.: Generation of gravity waves by jet-streams in the atmosphere, J. Atmos. Sci., 33, 1730-1738, 1976.

Markowicz, K. M., Flatau, P. J., Ramana, M. V., Crutzen, P. J., and Ramanathan, V.: Absorbing mediterranean aerosols lead to a large reduction in the solar radiation at the surface, Geophys. Res. Lett., 29, 1968, doi:10.1029/2002GL015767, 2002.

Meloni, D., di Sarra, A., Di Iorio, T., and Fiocco, G.: Influence of the vertical profile of Saharan dust on the visible direct radiative forcing, J. Quant. Spectrosc. Radiat. Transfer, 93, 397-413, 2005 . 
Meloni, D., di Sarra, A., Pace, G., and Monteleone, F.: Aerosol optical properties at Lampedusa (Central Mediterranean). 2. Determination of single scattering albedo at two wavelengths for different aerosol types, Atmos. Chem. Phys., 6, 715-727, doi:10.5194/acp-6-715-2006, 2006.

Meloni, D., di Sarra, A. Biavati, G., DeLuisi, J. J., Monteleone, F., Pace, G., Piacentino, S., and Sferlazzo, D.: Seasonal behavior of Saharan dust events at the Mediterranean island of Lampedusa in the period 1999-2005, Atmos. Environ., 41, 3041-3056, 2007.

Meloni, D., di Sarra, A.. Monteleone, F., Pace, G., Piacentino, S., and Sferlazzo, D. M.: Seasonal transport patterns of intense Saharan dust events at the Mediterranean island of Lampedusa, Atmos. Res., 88, 134-148, 2008.

Meywerk, J. and Ramanathan, V.: Influence of anthropogenic aerosols on the total and spectral irradiance at the sea surface during the Indian Ocean Experiment (INDOEX) 1999, J. Geophys. Res., 107, 8018, doi:10.1029/2000JD000022, 2002.

Pace, G., di Sarra, A., Meloni, D., Piacentino, S., and Chamard, P.: Aerosol optical properties at Lampedusa (Central Mediterranean). 1. Influence of transport and identification of different aerosol types, Atmos. Chem. Phys., 6, 697-713, doi:10.5194/acp-6-697-2006, 2006.

Podgorny, I. A., Conant, W., Ramanathan, V., and Satheesh, S. K.: Aerosol modulation of atmospheric and surface solar heating over the tropical Indian Ocean, Tellus, 52B, 947-958, 2000.
Raymond, D. J. and Fuchs, Z.: Convectively coupled gravity and moisture modes in a simple atmospheric model, Tellus, 59A, 627-640, 2007.

Reinking, R. F., Snider, J. B., and Coen, J. L.: Influences of stormembedded orography gravity waves on loud liquid water and precipitation, J. Appl. Meteorol., 39, 733-759, 2000.

Ricchiazzi, P., Yang, S., Gautier, C., and Sowle, D.: SBDART: A research and teaching software tool for plane-parallel radiative transfer in the Earth's atmosphere, B. Am. Meteorol. Soc., 79, 2101-2114, 1998.

Satheesh, S. K. and Ramanathan, V.: Large differences in tropical aerosol forcing at the top of the atmosphere and Earth's surface, Nature, 405, 60-63, 2000.

Sokolik, I. N. and Toon, O. B.: Direct radiative forcing by anthropogenic airborne mineral aerosols, Nature, 381, 681-683, 1996.

Zhou, M., Yu, H., Dickinson, R. E., Dubovik, O., and Holben, B. N.: A normalized description of the direct effect of key aerosol types on solar radiation as estimated from Aerosol Robotic Network aerosols and Moderate Resolution Imaging Spectroradiometer albedos, J. Geophys. Res., 110, D19202, doi:10.1029/2005JD005909, 2005. 